\title{
INVESTIGACIONES
}

\section{Discursos docentes sobre el vínculo con sus estudiantes: tensiones, enfrentamiento y distancia}

\author{
Teachers' discourses around the bond with students: \\ stress, confrontation and distance \\ Natalia Albornoz Muñoz, ${ }^{a}$ Rodrigo Cornejo Chávez ${ }^{a b}$ \\ a Universidad de Chile \\ Correo electrónico: natalbmu@ug.uchile.cl \\ ${ }^{\text {bC } C o r r e o ~ e l e c t r o ́ n i c o: ~ r o d r i g o . c o r n e j o @ u . u c h i l e . c l ~}$
}

\begin{abstract}
RESUMEN
El vínculo que se constituye entre profesor y estudiante es fundamental en el proceso educativo. Considerando aquello, el propósito de esta investigación es comprender los discursos que los docentes construyen en torno al vínculo con sus estudiantes. En el diseño metodológico utilizamos dos técnicas de producción de datos, el grupo focal y la entrevista episódica. Los participantes del estudio fueron docentes pertenecientes a cuatro escuelas secundarias de Santiago de Chile y para el análisis de los datos seguimos el modelo tridimensional propuesto por Norman Fairclough. Los principales resultados dan cuenta de que el vínculo con estudiantes es un ámbito complejo y que provoca tensiones en los docentes, quienes lo aluden como un enfrentamiento y se posicionan discursivamente en relaciones marcadas por la unidireccionalidad cuando se entrega algo al estudiante. No obstante, en el marco de coyunturas puntuales, estas relaciones entre profesor y estudiante transitan hacia la bidireccionalidad, como una transformación recíproca y potencial.
\end{abstract}

Palabras clave: vínculo profesor estudiante, pedagogía crítica, análisis crítico de discurso.

\begin{abstract}
The bond between teacher and student is essential in the educational process. Considering that, the purpose of this research is to understand the discourses that teachers build around the teacher-student bond. In the methodological design we used two techniques for data collection, the focus group and the episodic interview. Study participants were teachers from four secondary schools in Santiago de Chile and for data analysis we followed the threedimensional model proposed by Norman Fairclough. The main results show that the teacher-student bond is a complex area and that it causes stress on teachers, who refer to it as a confrontation and position themselves discursively in relations marked by directionality, giving something to the student. However, under specific situations, these relationships between teacher and student are moving towards bidirectionality, as a reciprocal and potential transformation.
\end{abstract}

Key words: teacher-student bond, critical pedagogy, critical discourse analysis. 


\section{INTRODUCCIÓN}

Existe consenso en considerar la relación entre profesor y estudiante como un aspecto central en la educación tanto formal como no formal. Asimismo, esta relación tiene un lugar importante en el proceso educativo que se desarrolla en la escuela, siendo estudiada por distintos autores y corrientes de pensamiento. Bajo esta premisa, la relación entre profesor y estudiante ha sido vista como un vínculo situado social e históricamente y que constituye un encuentro entre dos sujetos.

Pensar el vínculo situado, particularmente en el contexto educativo chileno, implica considerar las características y la realidad actual del espacio donde se despliega esta relación: las escuelas. Esto, sumado al importante lugar de los docentes en el proceso educativo nos invita a indagar desde su propia voz cómo describen y cómo se posicionan frente a ese vínculo con estudiantes.

Por lo tanto, en el presente artículo proponemos analizar el discurso de los docentes sobre el vínculo que construyen con sus estudiantes. Con este objetivo, haremos un breve recorrido por parte de la literatura que aborda el vínculo, continuado por una aproximación dialógica al mismo y, luego, entregaremos una perspectiva del vínculo entre profesor y estudiante situándolo en el escenario actual. Posteriormente, detallamos el enfoque y la metodología de investigación, seguido de los resultados del análisis. Finalmente, formulamos una discusión donde los resultados dialogan con los antecedentes revisados y planteamos algunas conclusiones.

\subsection{EL VÍNCULO PROFESOR ESTUDIANTE EN LA LITERATURA}

La relación entre profesor y estudiante ha sido abordada desde distintas disciplinas y teorías en los últimos años, habiendo consenso en que juega un rol fundamental dentro del proceso educativo. Así, esta relación es vista desde variados marcos conceptuales: como una variable del clima de aula que influye en los resultados de aprendizaje de los estudiantes (Murillo, 2003); como una relación intersubjetiva propia del proceso de aprendizaje y, por tanto, del desarrollo del educando (Bruner, 2006; Vigotsky, 1978); como un aspecto vincular decisivo en la permanencia escolar (Rosli \& Carlino, 2015); como un vínculo valorado por los estudiantes en su aprendizaje y participación (Albornoz, Silva \& López, 2015) y como una relación vincular definida por la mutua afectación (Martínez, 2007). Sobre la idea de relación vincular, vamos a situar nuestra investigación.

En términos generales, el vínculo educativo podría ser definido como un encuentro entre un agente educativo y un sujeto de la educación, no solo para que la cultura se vivifique y perdure, sino también para que se transforme (Núñez, 2003). De acuerdo a esta autora, como su origen etimológico indica, vinculum implicaría una 'atadura' o 'anillo' que trasciende una mera relación abriendo espacios para lo inédito y para la creación. Desde esta visión del vínculo educativo, los educadores se ubican en una posición paradójica, por un lado, deben enfrentarse a un sujeto en su particularidad y, por otro, cumplen una función de normatividad representando el orden social (Medel, 2003).

Asimismo, para Martínez, Collazo y Liss (2009) el núcleo propio de la relación profesor-estudiante "se constituye como un vínculo en tanto establece un entramado afectivo reconocido -registrado- por ambos términos de la relación vincular” (p. 407). 
En tanto constructo teórico, si bien el vínculo tiene su origen en el psicoanálisis y en la teoría de las relaciones de objeto, también es estudiado por otras corrientes. Por una parte, desde el constructivismo cognitivo se retoman algunos aportes de Bowlby que aluden al apego y al apego escolar, entendido como su aplicación en espacios educativos donde se repetirían ciertos patrones de los vínculos primarios en la relación profesor-estudiante (Pianta, 2001).

Por otra parte, el vínculo ha sido desarrollado por vertientes que hacen dialogar postulados del psicoanálisis con la psicología social. Por ejemplo, los aportes de PichónRivière (1985) para quien el vínculo, al ser un encuentro con el otro, constituye la mínima unidad de análisis de la psicología social. Bajo esta propuesta, el vínculo abriría un campo teórico complejo que no solo involucra aspectos afectivos o emocionales (Pichón-Rivière, 1985), sino también elementos del contexto socio-cultural, la historia de los sujetos, las relaciones de poder, las condiciones de trabajo, entre otras.

En ese sentido, el vínculo es una estructura triangular, formada no solo por los dos sujetos que se encuentran, sino también por un elemento implícito que es la cultura como tercero en la relación. El tercero, llamado el Otro histórico-social que entra al vínculo, podría ser la sociedad que instituye ciertos modelos y roles a los sujetos, quienes tienden a reproducirlos. Esta estructura, más o menos estable de relacionarse con otros, es susceptible a los cambios de cualquiera de sus elementos y es también conflictiva, en tanto implica una tensión agresiva entre el sujeto y el otro (Pichón-Rivière, 1985).

Como plantea Flores (2015), en el vínculo entre profesor y estudiante el Otro históricosocial sería la escuela como institución, el sistema educativo o la sociedad en general, quienes "crean expectativas en torno a la función que tendría la escuela, el tipo de sujeto que se pretende formar, la relación con el conocimiento y el rol tanto del profesor como de los estudiantes en el proceso educativo" (p. 60). Para este autor, el docente encarna el sistema de valores sociales y, en su condición de acatamiento de la estructura, tomaría un posicionamiento jerárquicamente superior y representaría una figura parental frente a los estudiantes (Flores, 2015).

Pensar la relación profesor-estudiante desde la teoría del vínculo implica considerar varios elementos, como la relación de mutua afectación, dialéctica y dinámica entre ambos sujetos, donde participa, además, el contexto como el otro cultural. Cabe señalar la convergencia entre los planteamientos de Pichón-Rivière y de Paulo Freire, que desde marcos disciplinares distintos, coinciden en aspectos centrales en torno al encuentro entre dos sujetos (Quiroga, 2001).

\subsection{UNA APROXIMACIÓN DIALÓGICA AL VÍNCULO PROFESOR-ESTUDIANTE}

Con una concepción dialéctica similar a la de Pichón-Rivière, Freire (1997) alerta sobre la imposibilidad de pensar la docencia sin "discencia". Es decir, la relación educadoreducando no se reduce a la relación sujeto-objeto, sino que son dos sujetos que con su acción enseñan y aprenden a la vez. De este modo, la relación educador-educando sería más bien un encuentro entre sujetos que se unen para crear y transformar.

Freire (1970) propone una educación liberadora basada en el diálogo entre educador y educando, como un "encuentro de los hombres para la pronunciación del mundo [que es] es una condición fundamental para su verdadera humanización" (p. 178). El autor, hace una dura crítica a la educación bancaria que entiende el conocimiento como una donación 
unidireccional de quienes saben hacia los ignorantes. Desde esta concepción, el margen de acción del educando es recibir y guardar los depósitos de saber, anulando su carácter creador y adaptándolo a la situación de dominación en que está sumergido (Freire, 1970).

Para Freire (1970) el fundamento de la educación bancaria es la antidialogicidad, expresada en una relación pedagógica sujeto-objeto que, mediante la división, la manipulación y la invasión cultural, conduce a la opresión de hombres y mujeres. En contraparte, la dialogicidad propia de la educación problematizadora y liberadora, se caracteriza por i) la colaboración, que requiere de la comunicación y de la confianza y es la base del encuentro entre sujetos para la pronunciación del mundo y su problematización; ii) la unión, en tanto relación solidaria entre oprimidos que solo juntos pueden hacerse conscientes de la realidad para liberarse; iii) la organización, para demostrar que el esfuerzo de liberación es una tarea en común; y iv) la síntesis cultural, como acción que se enfrenta a parte de la propia cultura de los oprimidos, a la parte alienada y alienante.

De este modo, el encuentro entre los dos sujetos de la educación implicar una actitud dialogal, una relación en la cual ninguno puede convertirse en mero objeto, pues se destruiría el diálogo y ya no habría formación sino domesticación (Freire, 1969). En ese sentido, del carácter dialógico del vínculo entre educador y educando, situado y condicionado sociohistóricamente, se deriva que el acto educativo es intrínsecamente político, en palabras de Freire (1997):

La raíz más profunda de la politicidad de la educación está en la propia educabilidad del ser humano, que se funde en su naturaleza inacabada y de la cual se volvió inconsciente. Inacabado y consciente de inacabamiento histórico, el ser humano se haría necesariamente un ser ético, un ser de opción, de decisión. (p. 104).

Por lo tanto, siendo el ser humano un ser inacabado, un ser condicionado, pero no determinado y cuya historia es una posibilidad para ser más, la educación liberadora, dialógica, tiene un papel fundamental en la toma de conciencia del inacabamiento.

Desde la pedagogía latinoamericana e inspirándose en la epistemología del presente potencial, Quintar (1998) propone la 'didáctica no parametral'. En este planteamiento, la autora explica cómo la educación puede llevar a la formación de sujetos erguidos o sujetos mínimos, es decir, a la expansión constante de la subjetividad o simplemente a la minimización del sujeto a través de parámetros y estándares (Quintar \& Zemelman, 2005).

Dichos autores diferencian dos pedagogías que operarían con fines contrarios: la pedagogía del bonsái y la pedagogía potencial. Por un lado, tenemos la pedagogía del bonsái, extendida en Latinoamérica y propia de un "contrato social en el que la educación fue instalada para subordinar y para oprimir" (Quintar \& Zemelman, 2005, p. 125). La metáfora del bonsái explica cómo a través de la pedagogía se va modelando con suavidad y cariño la raíz de lo que podría ser potencialmente un gran árbol y en su lugar se forma o deforma su raíz para mantenerlo pequeño, mínimo. Esto simboliza cómo los parámetros y el orden van mutilando el pensar, el imaginar, la conciencia y la potencialidad del educando. En palabras de Zemelman, una pedagogía consistente en "hacer seres humanos muy armoniosos, pero chiquititos, sin fuerza, sin capacidad de proyecto" (Quintar \& Zemelman, 2005, p. 128).

Por otro lado, la pedagogía de la potencia provoca el deseo de saber, impulsa a la búsqueda y a la capacidad de pensar, de interpretar, de comprender y aprehender el 
mundo de la vida, asumiendo los cuerpos teóricos heredados no como dogmas, sino como parte de la cultura que nos constituye y que puede ser transformada (Quintar, 2009). En la pedagogía de la potencia, el sujeto sería un transformador cuya subjetividad está en constante expansión, que no viene dada solo por la escolaridad, sino en el proceso educativo de toda su vida.

En virtud de la pedagogía de la potencia, Quintar $(1998,2009)$ define la didáctica no-parametral como una postura que "comprende el proceso de enseñanza en un proceso intencional de permanente promoción de ruptura de sentidos y significados en el propio devenir existencial" (Quintar, 1998, p. 41). La autora reivindica la didáctica, pese a que en la historia latinoamericana se la ha reducido a lo curricular, las competencias y los estándares, que expresan una pedagogía del bonsái. Según Quintar (2009), los sistemas educativos tienen una función ideológica de reproducción de información y conocimiento deshistorizado, que niega al sujeto y lo cosifica en su rol, ya sea de estudiante o de docente con lugares jerárquicos definidos en la organización laboral.

Sin embargo, desde la didáctica no paramentral el conocimiento se define como construcción de sentidos y significados que son históricos, en tanto el sujeto que los construye está "sujetado a su territorialidad contextual y a su subjetividad" (Quintar, 1998, p. 41). Así, el sujeto se articula en torno a su sujeción y a su capacidad de deseo promotora de acciones transformativas, tornándose en un ser dialéctico (Quintar, 1998). La educación aparece entonces como un espacio de resistencias y de lucha, de transformación y de un presente en potencia (Quintar, 2009).

La condición histórica asumida por la pedagogía de la potencia, es la que nos lleva a comprender que somos seres condicionados, pero no determinados y a "reconocer que la historia es tiempo de posibilidad y no de determinismo, que el futuro [...] es problemático y no inexorable" (Freire, 1997, p. 20). Cabe señalar, entonces, que la politicidad y la potencialidad de la educación toman un lugar en la transformación no solo de sujetos individuales sino sobre todo del mundo.

\subsection{EL VÍNCULO PROFESOR-ESTUDIANTE EN EL ESCENARIO SOCIOPOLÍTICO ACTUAL}

Conceptualizar el vínculo entre profesor y estudiante desde perspectivas críticas, dialógicas y en su potencial histórico, implica necesariamente comprender el contexto social más amplio donde se inserta. Por esta razón, haremos un breve recorrido por los acontecimientos y las características del actual contexto sociopolítico en educación.

El modelo educativo chileno, instalado en los años 80 en dictadura y sostenido por los gobiernos posteriores, ha sido reconocido internacionalmente como un cuasi mercado educativo que introdujo durante un largo período una lógica neoliberal (OCDE 2004; Verger, Bonal \& Zancajo, 2016). Este modelo se ha sustentado en cuatro pilares: i) el estado reducido a un rol subsidiario; ii) la creación de la figura del sostenedor educacional (privado o municipal) como administrador de recursos del estado; iii) el financiamiento vía vouchers; y iv) la reestructuración y privatización de la educación superior (Assaél et al., 2011).

Con el arribo de los gobiernos civiles en la década los 90, los pilares del sistema se mantuvieron y, además, se fortalecieron por medio de mecanismos tales como predominio de evaluaciones estandarizadas, modelos de gestión basados en resultados y competencia entre escuelas (Verger et al., 2016). 
La aplicación del modelo neoliberal en la educación chilena trajo graves consecuencias como desigualdad económica y sociocultural, estrechamiento del currículum y pérdida del sentido de la educación, privatización generalizada y declive de lo público, lo que generó condiciones que años después incubaron una crisis educativa (Assaél et al., 2015). Ante esta crisis, se erige un movimiento social que cuestiona el modelo educativo y la institucionalidad que lo ha sustentado (Donoso, Castro \& Alarcón, 2015).

Las movilizaciones por la educación alcanzaron dos puntos álgidos, el primero de ellos durante 2006 en la llamada "revolución pingüina", protagonizado por estudiantes de educación secundaria, que levanta demandas tales como el fin al lucro en educación, fin de la municipalización y fin al modelo de mercado. El 2011 fue otro año clave de movilización, incluso con mayor masividad, en que los actores profundizaron las críticas al modelo y a la respuesta insuficiente de la clase política, exigiendo gratuidad en la educación superior y disputando los proyectos educativos.

Frente a las demandas y propuestas del movimiento, los distintos gobiernos han respondido por medio de iniciativas legislativas que en su conjunto han constituido un "nuevo marco regulatorio para la educación escolar" (Cornejo et al., 2015). Esta agrupación de leyes, si bien dice recoger las consignas del movimiento social, no modifica los pilares del modelo. De ese modo, los intentos de reformas mantienen la lógica de financiamiento a la demanda, la igualdad de trato público-privado, la competencia entre escuelas y el rol reducido del estado (Assaél et al., 2015; Donoso et al., 2015).

Frente a las respuestas desfavorables de la clase política, las movilizaciones continuaron y al interior de las instituciones escolares, especialmente secundarias, se fueron tensionando y contraponiendo los discursos de docentes y de estudiantes (Cornejo \& Insunza, 2014). Esta tensión fue provocada, principalmente, porque los docentes habían mantenido un discurso apegado al orden hegemónico minimizando la politicidad de su trabajo, a diferencia de los estudiantes que eran críticos al orden y politizaban sus luchas, apuntando a la transformación social (Cornejo \& Insunza, 2014).

Considerando los antecedentes antes señalados, en la presente investigación nos planteamos comprender los discursos docentes en torno al vínculo que construyen con sus estudiantes en este contexto socioeducativo.

\section{MÉTODO}

Para responder al objetivo planteado, propusimos un diseño cualitativo de investigación, que nos permitía considerar los discursos de los docentes, su experiencia y los textos que surgen de ella. En ese sentido, intentamos relevar la comprensión de la realidad social desde las dimensiones subjetivas e intersubjetivas de los propios sujetos en estudio (Flick, 2004).

Particularmente, en coherencia con el marco teórico adoptado, planteamos la investigación desde el enfoque del análisis crítico de discurso [ACD]. El ACD supone vislumbrar al sujeto -en este caso, docentes- inmerso en un entramado de relaciones, identidades y conflictos sociales y sobre todo comprender cómo se expresan, mantienen o transforman determinados grupos sociales en cierto contexto (Calsamiglia \& Tusón, 1999). En consecuencia, podemos entender los discursos docentes no solo en relación con la reproducción del orden discursivo, sino también en sus fisuras contra-hegemónicas, abriendo las potencialidades de transformación de ese orden (Fairclough, 2001). 


\subsection{PARTICIPANTES}

Los participantes del estudio fueron docentes pertenecientes a escuelas secundarias de la Región Metropolitana de Santiago de Chile. Estos establecimientos forman parte de la muestra de una investigación mayor en la que se inserta el presente estudio y fueron definidos en base a dos criterios que estructuran realidades educativas distintas: tipo de dependencia administrativa, municipal o particular subvencionada, y nivel de selectividad de los estudiantes, selectivo o no selectivo.

El cruce de estos criterios delimitó cuatro contextos relevantes de conocer para el problema de investigación, que se muestran en la Tabla 1:

Tabla 1. Participantes por contexto educativo

\begin{tabular}{|c|c|c|c|}
\hline \multirow{2}{*}{\multicolumn{2}{|c|}{ No Selectivo }} & \multicolumn{2}{|c|}{ NIVEL DE SELECTIVIDAD } \\
\hline & & Selectivo & \\
\hline \multirow{2}{*}{ 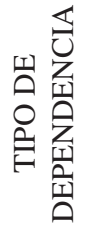 } & Municipal & $\begin{array}{c}\text { Escuela A } \\
2 \text { mujeres; } 5 \text { hombres }\end{array}$ & $\begin{array}{c}\text { Escuela B } \\
5 \text { mujeres; } 1 \text { hombre }\end{array}$ \\
\hline & $\begin{array}{c}\text { Particular } \\
\text { Subvencionado }\end{array}$ & $\begin{array}{c}\text { Escuela C } \\
3 \text { mujeres; } 4 \text { hombres }\end{array}$ & $\begin{array}{c}\text { Escuela D } \\
5 \text { mujeres; } 1 \text { hombre }\end{array}$ \\
\hline
\end{tabular}

Fuente: elaboración propia.

\subsection{PROCEDIMIENTO Y TÉCNICAS DE PRODUCCIÓN DE DATOS}

Como una primera entrada a los discursos docentes, realizamos grupos focales con 6 y 7 participantes por cada establecimiento, seleccionados por un criterio de heterogeneidad de género, disciplina y edad (Valles, 1999). Esta técnica nos permitió introducirnos en los saberes, las racionalidades y las prácticas cotidianas (Canales, 2006) de los profesores. Los cuatro grupos focales fueron audiograbados y transcritos para su análisis.

A partir del análisis preliminar pudimos extraer categorías generales y temas que eran necesarios de profundizar especialmente en experiencias relacionadas con el vínculo. Por esta razón decidimos indagar mediante una segunda técnica de producción de datos, la entrevista episódica y, para ello, seleccionamos a un docente de cada uno de los grupos focales. Esta técnica fue una herramienta acertada, puesto que presta atención a aquellos episodios o situaciones donde el entrevistado ha tenido experiencias significativas y permite el despliegue de aspectos íntimos y emocionales, que solo se habían mencionado en los grupos focales (Flick, 2004).

Una vez finalizadas las entrevistas episódicas, procedimos a transcribir el material registrado en audio previa autorización de los participantes. En los registros escritos se modificaron los nombres de los participantes y de las escuelas con el fin de resguardar la confidencialidad y el anonimato. 


\subsection{ANÁLISIS DE LA INFORMACIÓN}

Para el análisis de los datos utilizamos el modelo tridimensional de Fairclough (1989) enmarcado en el Análisis Crítico del Discurso. Este modelo plantea tres momentos de análisis o dimensiones: i) análisis lingüístico del texto; ii) análisis interpretativo del discurso y iii) análisis explicativo relacionando el discurso con el contexto social más amplio. Estas dimensiones son solo distinciones procedimentales y no deben ser entendidas como etapas cronológicas, ya que el análisis es un proceso con pasos que se entrecruzan inevitablemente (Fairclough, 1989).

Específicamente, nuestro foco estuvo puesto en el vocabulario, las funciones del lenguaje, las estructuras gramaticales más utilizadas por los docentes y las figuras retóricas. A partir de esto se analiza el discurso como práctica social en la discusión que realizamos al final de este escrito.

\section{RESULTADOS}

Los resultados del análisis se articulan en torno a tres núcleos que emergieron de los discursos docentes: i) el carácter complejo del vínculo; ii) el vínculo vivenciado como enfrentamiento; iii) la relación unidireccional y/o bidireccional en el vínculo profesorestudiante.

\subsection{LA COMPLEJIDAD DEL VÍNCULO CON EL ESTUDIANTE: INCERTIDUMBRE Y TENSIÓN}

A partir de una primera mirada a los textos, podemos distinguir cierta dificultad en los hablantes para describir su vínculo con el estudiante, que estaría señalando precisamente la complejidad del tema, que se vuelve incluso fuente de tensiones. A modo de ejemplo, encontramos a continuación:

M2: es como esquizofrénico estar pensando todo el rato si es así le va a causar esto o uno también de repente juega, nosotros jugamos, marqué a esta alumna o ellos la marcan a uno también, también ocurre, no y no es chiste, porque uno está en contacto siempre con seres humanos y uno, el profesor está siempre demandado, demandada [...] uno siempre tiene la demanda de otra persona, entonces ese juego es muy, es muy complejo para uno psicológicamente y también para ellos. (Fragmento 1. Grupo Focal Establecimiento B).

A nivel de vocabulario, se alude a la relación con los estudiantes mediante palabras como un juego mиy complejo, complicado, donde siempre se está demandando y se es demandado a la vez, dando cuenta de una tensión vivenciada por la hablante. Además, la comparación de esta tensión con algo esquizofrénico podría suponer una sensación de estar dividido o escindido mentalmente respecto al vínculo.

Algo similar menciona la siguiente docente:

M5: uno que no anda todo el tiempo efectivamente pendiente, y además hay ciertas valoraciones que uno no conoce, entonces algunos hacen la clase y de ahí en adelante 
se genera como una, es como una bola de nieve que puede terminar, no sé, en una idea increíble como también puede ocurrir que no se genere nada y terminen los lazos y se fue y nunca les pasó nada, nunca le importó, nunca más se acordó eh, hay otras relaciones que pasan y uno sí se puede dar cuenta de que en estos casos uno puede terminar siendo el papá, la mamá, el confidente, el psicólogo, [...] entonces es súper complejo porque no se da como una uniformidad en cuanto a eso. (Fragmento 2, Grupo Focal B).

Ante la imposibilidad de ejercer control total en este vínculo complejo, la hablante manifiesta que es imposible estar todo el tiempo pendiente de cómo puedan sentir o percibir los estudiantes y no pensar o no cuestionarse sobre el tema sería una forma de eludir la inseguridad que este puede provocar. En ese sentido, lo que la docente llama falta de uniformidad en las relaciones con los estudiantes, expresaría la incertidumbre e incluso la angustia que causa el no tener certezas sobre el vínculo y su impacto en los estudiantes.

Igualmente, la metáfora de la bola de nieve ejemplifica las consecuencias de vincularse con los estudiantes: una bola de nieve va creciendo de forma vertiginosa a medida que avanza y puede tener efectos inciertos. Estos efectos inciertos se polarizan en el texto: por un lado, podrían derivar en una idea increíble, que el docente termine siendo el papá, la mamá, el confidente o el psicólogo y, por otro lado, podrían llevar a que no se genere nada, a que se terminen los lazos. Es decir, la bola de nieve que metaforiza la relación con el estudiante puede permitir la construcción de un vínculo muy cercano, incluso familiar y con relativa permanencia o simplemente llevar a la nada.

Pese a la incertidumbre que trae consigo pensar el vínculo con el estudiante, trabajar con personas se vuelve también fuente de satisfacción para los docentes, y algo que da sentido y se vuelve foco de su trabajo:

M3: yo creo que los alumnos finalmente te van revitalizando como para que uno se mantenga en esto y finalmente el sentido de la educación en sí misma está centrado en ellos, no en uno, sino que uno tiene que eh, no sé po', focalizarse en ellos, en algún momento uno perdió ese foco. (Fragmento 3, Grupo Focal B).

M4: en los momentos malos, por lo menos míos, los alumnos han sido un pilar, un sostén, súper fuerte, sin ellos saberlo, sin tener la más mínima idea [...] es simplemente el contacto ese, llegué más o menos hecha pebre a la sala, me empiezo a entregar y se me van todas. (Fragmento 4, Grupo Focal B).

Los fragmentos citados expresan la importancia de la relación con los estudiantes, ellos revitalizarían a los docentes, serían un pilar, un sostén, serían el foco de la educación. En ese sentido, se va describiendo un vínculo que trasciende el mero espacio laboral e influye en decisiones de vida de los docentes. Por ejemplo, la hablante del fragmento 4 al utilizar la metáfora de llegar hecha pebre a la sala -que simboliza el estar destrozada, despedazadadaría cuenta de una sutil contraposición entre la destrucción y la recomposición, el volver a la vida que impulsan los estudiantes.

Entonces, el vínculo adquiere un lugar central en el trabajo de los docentes, a pesar de la dificultad para describirlo o incluso nombrarlo, y cuyas descripciones fluctúan entre conceptos tales como la retribución, la revitalización, lo esquizofrénico y lo complejo. 


\subsection{EL VÍNCULO VIVENCIADO COMO ENFRENTAMIENTO Y LA NECESIDAD DE SER ESTRATÉGICO}

En el marco del vínculo con los estudiantes, aparece la metáfora de la guerra por medio de palabras como la lucha constante o tener que guerrear todos los días. Esta analogía entre lo que sucede en el aula y un combate evidencia una función relacional del lenguaje, donde los docentes se posicionan contra los estudiantes y contra el mundo. En los siguientes fragmentos podemos apreciarlo:

H4: pero te digo para mí yo siento que uno tiene que tener pasión para esto, porque si no la verdad.

H1: Que sabes que vas a venir a guerrear todos los días. (Fragmento 5, Grupo Focal A). H1: nosotros con nuestro eh romántico querer cambiar el mundo vamos al aula $a$ luchar unos más conscientes que otros porque es lucha en el fondo, así lo siento yo, el encuentro en el aula. (Fragmento 6, Grupo Focal C).

En ambas citas se manifiesta una función identitaria del discurso que expresa cómo se ven a sí mismos los docentes, como románticos y apasionados luchadores activos contra todo lo perjudicial que se condensa en el aula y se expresa en sus estudiantes.

La idea de la lucha y el enfrentamiento, llevada a una posición más extrema, puede ilustrarse a través de un neologismo en el siguiente fragmento que fue producido en el contexto municipal no selectivo. El hablante, al relatar una situación puntual de violencia, metaforiza una visión sobre el estudiante, sobre el lugar del docente y, en general, sobre el vínculo como guerra:

H1: Ayer yo estaba haciendo mi taller de básquetbol y te prometo delincuentes, alumnos nuestros, con el dolor que me significa plantear la expresión delincuentes [...] estamos necesitando algo de gendarmería, porque el director se atrevió en alguna oportunidad, y no sé si, yo sé que lo dijo sentidamente, o sea con un dolor tremendo, cuando dijo que la educación municipal se está senamizando, como concepto Yo tuve que sacar a mis chiquillos del básquetbol porque una guerra, no había caso, es que no te digo lo riesgoso que era, que no fue capaz ni inspectoría general, no fue capaz qué sé yo, los paradocentes, a quienes les informé, véngase chiquillos los míos para acá, salgamos de aquí, porque los peñascazos nos van a llegar a nosotros. (Fragmento 7, Grupo Focal A).

El docente declara que la educación se está senamizando, en alusión a la labor del Servicio Nacional de Menores (SENAME) que trabaja con jóvenes infractores de ley. De forma más explícita aún, el hablante asevera que en el incidente aparecen alumnos delincuentes y con la expresión "te prometo", da mayor fuerza a su afirmación. Además, él plantea como necesidad que en los establecimientos exista gendarmería, otro concepto propio de la institución carcelaria chilena, pues son los gendarmes los encargados de vigilar a los prisioneros en las cárceles. Así, se evidencia una función ideacional en las palabras utilizadas por el hablante, donde se asemeja al estudiante con el delincuente, al docente con el gendarme y, de forma indirecta, a la escuela con la cárcel. Se evidencia también una función relacional, donde claramente el estudiante sería enemigo del docente. 
En el contexto de enfrentamiento descrito por los docentes, un aspecto llamativo de los discursos tiene relación con las estrategias que ellos siguen para lograr sus propósitos. A continuación, se presentan algunas:

M2: mi objetivo también dentro de todo lo que se ha dicho, lo procedimental, lo actitudinal, el tema de que aprendan y todo está también en conquistarlos, con tal de tenerlos conmigo, de que lleguen, claro, no me aplauden, pero tratar de que lleguen conmigo y de que estén bien conmigo, porque la verdad es que es súper complejo ser la profesora de literatura, hablarles de literatura para ellos es súper árido. (Fragmento 8, Grupo Focal D).

H2: cuando intentábamos cambiar los esquemas de las clases, estamos pensando en cómo, si la anterior [clase] no me resultó que fue estilo cátedra, cómo hacer una que sea más participativa, cómo cambiar los estilos de la sala. Entonces es como un desafío constante de ser seductores con los contenidos que se tienen que entregar obligados por el tema del currículum. (Fragmento 9, Grupo Focal C).

Entre estas estrategias están, por ejemplo, lograr conquistar y seducir al estudiante para que se involucre con los contenidos que incluso pueden llegar a ser muy áridos. Por una parte, el adjetivo árido que la hablante del fragmento 8 utiliza para describir los contenidos de la clase se utiliza como sinónimo de aburrido, insípido, sin mayor atractivo, algo seco e infértil. En ese sentido, el término tiene gran valor expresivo, pues daría cuenta de cómo ella significa y evalúa ese aspecto de su realidad, los contenidos. Igualmente, cuando el hablante del fragmento 9 alude a tener que entregar los contenidos obligados por el currículum, se evidencia una suerte de distanciamiento respecto a aquello que se entrega en la enseñanza, como si fuera alguien externo al aula quien impone dichos contenidos.

Por otra parte, llama la atención el vocabulario relacionado con la seducción, la conquista y el encanto como estrategias de los docentes para hacer frente a los estudiantes. Estos sustantivos conjugados como verbos en los fragmentos darían cuenta de una suerte de juego emocional al que recurren los docentes para persuadir a los estudiantes. Además, dichos conceptos denotan cierta ilusión, artificio o actuación de parte de los hablantes, quienes finalmente utilizan esta actitud como instrumento para el logro de los aprendizajes.

\subsection{RELACIÓN UNIDIRECCIONAL SUSTENTADA EN LA CARENCIA DEL ESTUDIANTE Y RELACIÓN BIDIRECCIONAL COMO GERMEN}

En una primera instancia los docentes comienzan describiendo los grandes objetivos de su trabajo relacionados, en la mayoría de los casos, con la formación de personas y sujetos con valores y conscientes. Si bien esta idea se asocia a una tarea atribuida socialmente a la docencia, cabe destacar que la concepción contenida en ese 'deber ser' supone una transmisión o enseñanza de parte del docente al estudiante en un sentido unidireccional:

H4: El objetivo principal es formar personas. Formar personas y la asignatura es como una herramienta... [...] En forma personal si yo enseño matemáticas, porque mi habilidad es matemática, mediante la matemática puedo formar personas que sean ordenados, que piensen, que sigan un método científico y un montón de cosas [...] 
porque la verdad que con todas las vorágines de que hay san google... lo ayuda todo, pero no lo soluciona, eh nosotros formamos personas. (Fragmento 10, Grupo Focal A).

En la formación de personas, las asignaturas serían herramientas para potenciar determinadas características en los estudiantes como ser ordenados, pensar, seguir un método. Además, el objetivo de formar personas sería específico de la labor docente, que no se podría suplir con otras fuentes de información como san google. En este caso el estudiante aparece como algo a moldear y un sujeto pasivo que recibe la acción de un sujeto agente, correspondiente al docente.

Asimismo, podemos observar cómo esa idea de formar personas se sustenta en la visión de un estudiante en falta o desorientado:

M3: La docencia primero que nada la definiría como actividad social, en la cual, como actividad social, se involucra con el estudiante y este además de ser guiado, porque no tienen una identidad profunda, porque es un feedback de contenidos o emociones eh... no solamente el conocimiento, sino que también experiencias, y que se van forjando a través de los años de educación. (Fragmento 11, Grupo Focal C).

M2: ahí veís el resultado de la real educación, porque son cabros que no saben organizarse, que no tienen claros sus intereses, que no tienen claros sus gustos, que tienen temor, que no y que son súper también eh va a sonar fea la palabra, pero son súper fascistas también entre ellos. (Fragmento 12, Grupo Focal C).

El tono declarativo de los enunciados y su estructura gramatical, dan cuenta de varios aspectos: primero, tienen una función ideacional sobre la figura del estudiante como sujeto en falta, sin una identidad profunda, que no es persona aún y que a través de la educación podría, eventualmente, llegar a serlo. Segundo, expresan una función relacional donde el docente se vincula con el estudiante para entregar algo o enmendar aquello que está mal, que está errado o inconcluso y al que debe guiar.

Esto se evidencia con el tono declarativo de la hablante del fragmento 12 sobre el carácter fascista de los estudiantes, término que representa una carga ideológica que amerita profundizar. Por un lado, el carácter fascista no está definido en el extracto, pero se enumera junto con otras características mencionadas previamente que no tienen el mismo valor expresivo que el fascismo, tales como no tener claros los intereses o no tener claros los gustos. Este tratamiento del término en relación de sinonimia con otros adjetivos reduciría la fuerza expresiva de la palabra fascismo, naturalizándola en cierta forma. Por otro lado, es una acusación que no aparece sustentada en argumentos de ningún tipo y la misma hablante atenúa su posible impacto en los demás participantes con la advertencia previa "va a sonar súper fea la palabra, pero...".

De igual modo, encontramos otros extractos donde es explícita la idea del docente poseedor de aquello que falta al estudiante, configurando un tipo de vínculo más bien unidireccional. Los siguientes fragmentos dan cuenta de ello:

H1: lamentablemente, ellos [los estudiantes] nos informan de muchas cosas, eh, ellos tienen información hoy día, porque tienen un poco más de tiempo, pero nosotros tenemos, eh, un poco más el razonamiento para, versus ellos que son un poco más vehementes en el actuar. (Fragmento 13, Grupo Focal B). 
H4: y su visión de mundo [de los estudiantes] cierto, que es tan finita llega hasta aquí, llega hasta aquí. Cuando yo amplío mi visión ¿cierto? Cuando quiero cosas por supuesto que también amplío mis necesidades ¿cierto? Cuando amplío mi visión filosófica puedo tener necesidades filosóficas, pero aquí se vive hambre, se vive lo físico, aquí en este colegio, aunque ustedes no lo crean hay cabros que pasan hambre. (Fragmento 14, Grupo Focal C).

En el fragmento 13, el hablante insinúa doblemente la relación de posesión-no posesión, al señalar que los estudiantes tienen información debido a que tienen más tiempo, aseveración que aparece como un hecho objetivo y como causa-consecuencia -tener tiempo llevaría a tener información-. Esta afirmación sitúa a los estudiantes como desocupados, lo cual en su condición de estudiantes sería posible, pero no necesariamente en su condición de sujetos que viven y comparten en otros espacios distintos al espacio escolar. Adicionalmente, el hablante polariza dos conceptos: el razonamiento, algo que sería positivo y que tendrían los docentes, versus la vehemencia como lo negativo que tendrían los estudiantes.

Algo similar ocurre en el fragmento 14, donde el estudiante es definido por su visión finita del mundo que llega hasta aquí, lo cual se explicaría por las necesidades básicas que no le permiten tener necesidades más filosóficas, no le permiten ir más allá. Con el uso de la primera persona singular en la oración cuando quiero cosas filosóficas, también amplío mis necesidades, se insinúa que el docente sí tiene esas necesidades que 'van más allá'. Se desprende así, una función relacional de asimetría entre profesor y estudiante sustentada en la carencia del estudiante, que al parecer se limita a recibir aquello que el docente puede entregar. Este supuesto sobre un vínculo unidireccional y asimétrico que se desprende de los discursos parece ser homogéneo en los textos analizados.

A pesar de esas descripciones en torno al vínculo, en una segunda instancia podemos apreciar cómo en otros fragmentos cambian las referencias al vínculo entre profesor y estudiante. La posición del profesor y del estudiante en la relación se modifica y toma un sentido más bien bidireccional; ya no hay un traspaso desde un lado hacia el otro, sino que se manifiesta mayor reciprocidad y en algunos casos emerge el estudiante como un sujeto presente y no una persona a moldear. Cabe señalar que este segundo grupo de alusiones al vínculo más bidireccional es incipiente y corresponde más bien a una heterogeneidad en términos discursivos.

Sobre el aspecto pedagógico, en el fragmento que sigue se aprecia la necesidad de una interacción entre profesor y estudiante para que se produzcan los aprendizajes:

M6: o sea, es tan simple que de repente uno hace una clase, no te sale bien y uno dice, pucha algo hay que cambiar, y esa transformación permanente en la práctica docente es de las cosas más importantes con la relación profesor alumno, o sea, que al final uno va transformando su práctica de acuerdo a lo que uno ve que produce en ellos y lo que ellos producen en uno también. (Fragmento 15, Grupo Focal B).

Se desprende del extracto una función relacional del discurso que insinúa cierta simetría entre profesor y estudiante, aunque no sea explícito, expresaría la importancia de este último en la relación pedagógica.

De forma más clara, la idea de transformación permanente de la práctica docente gracias a la relación profesor-alumno que enuncia la hablante del fragmento 15, sitúa al 
vínculo en el ámbito pedagógico y da cuenta de cierta retroalimentación o reciprocidad, donde el estudiante también juega un rol fundamental.

Otro de los conceptos relevados en el marco de los vínculos entre profesor y estudiante es el respeto recíproco, como un elemento necesario dentro de la relación. Por ejemplo:

M4: yo creo que en mi caso el objetivo en lo cotidiano, intento ser consecuente y coherente y que ellos vean que, en mi área, importa mucho la comunicación, el respetarnos mutuamente, ellos ven que yo también lo digo, entonces hay una coherencia de lo que les pido a ellos y cómo yo voy respondiendo a esas exigencias. (Fragmento 16, Grupo Focal D).

En el extracto, la docente da cuenta de un respeto que no solo es exigido al alumno, como podría ocurrir en una relación de autoridad tradicional, sino más bien enfatiza la idea de un respeto mutuo, que se retroalimenta entre profesor y estudiante. También aparece en el fragmento la figura del docente que debe ser consecuente y coherente frente a sus estudiantes, que responde tal como deben responder ellos. Podemos distinguir, entonces, una función relacional en el texto que expresa cierta simetría o bidireccionalidad en el vínculo.

Más allá de lo pedagógico y de lo relativo al respeto, un tercer aspecto que se enuncia en las entrevistas es la transformación personal ya no solo del estudiante sino del propio docente a partir del vínculo entre ambos, como veremos:

Mario: En 2006 a mí me pasan un [curso] súper complejo, desde mi mirada, yo en ese momento estaba recién titulándome, desde la mirada bien tradicional de profe, yo no podía pasar mis contenidos, chocaban mis planificaciones con la realidad, decía qué carajo, llevaba dos meses en lo mismo. Cómo va a ser tan difícil implementar música, y en un momento hago clic y digo, ya chicos saben qué, tiro la esponja, y digo ¿qué quieren hacer? Queremos esto y esto otro, y todo lo que pedían no tenía nada del otro mundo, tenía que ver con música, tenía que ver con las expectativas de ellos, y esa fue una experiencia potentísima, porque empezamos a trabajar, fue bajarme el ego, fue bajarme de un montón de estructuras academicistas y empezamos y se generaron cosas maravillosas, en el patio con público, eran los músicos [del liceo]. (Fragmento 17, Entrevista Episódica C).

En el fragmento 17 el entrevistado relata un episodio crítico, cuando estuvo a punto de rendirse o tirar la esponja porque chocaban sus planificaciones con la realidad. La solución a esta situación problemática estaba finalmente en los propios estudiantes, que propusieron y construyeron junto al profesor, quien fue cambiando durante el proceso. Los estudiantes lograron bajar del ego al docente, bajarlo de las estructuras academicistas y de la mirada tradicional, lograron de cierta forma transformar la práctica y las concepciones del docente. Por lo tanto, podemos inferir una función relacional que posiciona al docente como alguien dispuesto a escuchar, a recibir o a transformarse a partir de lo que los estudiantes tengan para enseñar.

Lo interesante en este punto es la inversión de la relación unidireccional antes presentada y el deber del docente de formar personas en falta o inconclusas. Acá habría un aprendizaje en términos personales a partir de lo que los estudiantes tengan para enseñar, en ese sentido 
se reitera el verbo escuchar. Esta escucha, además, es dotada de un significado profundo, pues tendría consecuencias reales en el docente, no solo sería una actuación necesaria para empatizar con el estudiante.

Otra dimensión de los discursos docentes en la que se modifica la relación unidireccional profesor alumno emerge cuando estos aluden al contexto social e histórico más amplio, específicamente la movilización social por la educación. Se modifica en cierta forma el campo semántico asociado al vínculo y se visibiliza al estudiante como sujeto, al menos a nivel discursivo.

Así lo enuncia el siguiente episodio, que continúa el fragmento expuesto anteriormente y que se desarrolla cuando el docente replica la estrategia de preguntar a los estudiantes, pero ahora en el marco de "la revolución pingüina" del 2006 y a nivel de liceo:

Mario: El 2006 es el levantamiento de los pingüinos... dentro de los planteamientos de los pingüinos está que la $\mathrm{JEC}^{1}$, las horas de jornada escolar completa vuelvan a su espíritu inicial que es la formación integral del estudiante, ¿ya? No más matemática y más lenguaje, eso implicaba mover el... el currículum ¿cierto? Entonces acá me preguntan, me acuerdo que a mí me proponen, no sé por qué carajo el director de esa época me pregunta qué se me ocurre a mí. Yo le planteo así, tal cual, a mí no se me ocurre nada, ¿por qué no le preguntamos a los cabros qué se les ocurre? Y eso fue clave porque desde ahí nace la propuesta y empiezan los chiquillos a participar y empiezan a ver cómo y el 2007 empieza a funcionar, el 2008 ya entramos después con un circuito con el Consejo de la Cultura a trabajar [...] Y eso fue el puntapié inicial para un proceso, maravilloso, yo creo que como experiencia de vinculación con los otros, en este caso en general con los estudiantes de esa generación, yo creo que oh es increíble, increíble. (Fragmento 18, Entrevista Episódica C).

En este caso, el episodio es gatillado por una coyuntura de movilizaciones estudiantiles y que, por medio de la demanda de volver al espíritu inicial de la Jornada Escolar Completa, interpela a los directivos del establecimiento a replantear aspectos del currículum. En este marco, el docente propone preguntarles a los cabros qué se les ocurre y se genera un proceso calificado con adjetivos de gran valor expresivo como maravilloso o increíble, que darían cuenta de la evaluación positiva que hace el hablante de la experiencia. Además, en el fragmento se alude explícitamente a la increíble vinculación con los otros que se genera a partir de esa experiencia.

En la misma línea, encontramos fragmentos que aluden a las movilizaciones, enfatizando más bien en cómo se distancian las posiciones de profesores y estudiantes en esas coyunturas:

M2: [la movilización] me ha llamado la atención y me ha servido como plataforma de entrada, cierto, a ciertas materias y todo, efectivamente los chiquillos tienen un sentido más crítico de la realidad y por eso yo creo también que la mayoría se adscribe a estas movilizaciones, aunque igual hay un porcentaje de alumnos que lo hace por masa nomás, pero sí me ha llamado más la atención que en ese sentido, los estudiantes

En 1997 se promulga la ley de Jornada Escolar Completa [JEC], que destina recursos para extender la jornada escolar y cuyas pretensiones originales eran mejorar la calidad educativa y la gestión docente. 
a los profes, por lo menos de acá, nos dan cátedra, o sea ellos son mucho más pro en ese sentido y que siento que no sé, de repente a nosotros nos pueden estar poniendo el pie encima y nosotros nos cruzamos de brazos y nos agachamos para que sea más fácil y ahí sí me ha impactado y me ha llamado la atención y a veces me ha molestado también un poco la inercia con la que se deja llevar el gremio en general. (Fragmento 19, Grupo Focal B).

H1: Los jóvenes, eh, se ha trabajado de un tiempo a esta parte en ese vínculo para que, para poder unir esas dos posiciones y encarnar una sola línea, ambas corrientes fuertes, los profesores son fuertes acá y los alumnos son fuertes también y están bien organizados, entonces eso se ha logrado tratar hace un par de años atrás. (Fragmento 20, Grupo Focal B).

En el caso del fragmento 19, la docente señala que los estudiantes tienen un sentido más crítico, son más pro que los docentes e, incluso, en relación con la movilización serían ellos quienes les dan cátedra. Esto es interesante, porque del texto se desprenden claramente las tres funciones del discurso: primero, la función ideacional que ve a los estudiantes como sujetos críticos y conscientes -ahora, no en el futuro-. Segundo, una función relacional, mediante la frase los estudiantes nos dan cátedra a los profesores que enuncia una relación de mayor simetría, ya no es solo el docente el que enseña, sino que el aprendizaje sería recíproco. Tercero, una función identitaria, ya que la hablante caracteriza la postura de los docentes como sumisa e inerte frente al aplastamiento.

Otra intervención sugerente es la de H1 en el fragmento 20, quien indica que en su liceo se está trabajando para unir esas dos posiciones fuertes y encarnar una sola línea: profesores y estudiantes. Esta idea da cuenta de una posibilidad de mayor vinculación, en torno a una postura en común de dos actores que aparecen, por lo general, en lugares distintos y hasta contrarios dentro de la institución escolar. Así, emerge en algunos momentos el vínculo bidireccional de forma embrionaria y con potencial de alianza que apunta a la transformación. Aunque la enunciación de otro tipo de vínculo se produce principalmente en torno a contextos fuera del aula y en relación con la movilización, esto no deja de ser significativo en términos discursivos, como veremos en la discusión.

\section{DISCUSIÓN Y CONCLUSIONES}

Para comenzar podemos mencionar que los discursos docentes aluden al vínculo como un ámbito que provoca incertidumbre y tensión. Por una parte, el vínculo aparece en los discursos como una relación difícil de abordar por la complejidad de tratar con otro ser humano que demanda y es demandado. Esta relación para los docentes implica guerrear con el estudiante en una lucha constante y frente a la cual debe desplegar distintas estrategias. Por otra parte, el vínculo es una fuente de gratificaciones y revitalización, una forma de mantenerse joven y una razón para continuar en la docencia, pese a las condiciones adversas. Según los discursos, el vínculo es, incluso, un aspecto que otorga sentido al trabajo del docente.

De ese modo, el vínculo aparece como una paradoja para los hablantes que expresa contradicción, conflicto y complejidad. Así, adquieren sentido los planteamientos de Núñez (2003) y Medel (2003), para quienes el docente se encuentra en una posición paradójica 
respecto al estudiante. Para ellas, la posición paradójica se debe a que el docente representa las normas y valores de la sociedad, por un lado, y enfrenta las particularidades de los estudiantes en tanto sujetos, por otro.

Podemos apreciar también, que el vínculo entre profesor y estudiante se configura a través de los discursos como un núcleo o un eje fundamental en torno al que se organiza la labor del docente, aun cuando se le atribuyan efectos inciertos. Esta centralidad puede entenderse desde los aportes de Martínez (2007) quien plantea al vínculo como un entramado afectivo-doloroso entre los dos sujetos de la educación, constitutivo de la labor y núcleo articulador del trabajo docente.

El vínculo, además de complejo, se presenta en primera instancia como una relación unidireccional mediante la cual el docente forma personas inconclusas, en falta, sujetos que aún no son tal, a quienes debe entregar algo. Esta entrega, podría interpretarse desde una lógica de la educación bancaria que critica Freire (1970), pero aquí el docente no solo transmitiría conocimientos, sino también valores o afectos. Según los discursos analizados, en esta relación el docente iría moldeando al estudiante. Este vínculo unidireccional llevaría a modelar al estudiante, así como se modelan las raíces de un árbol para deformarlo en la metáfora del bonsái propuesta por Quintar (1998, 2009).

Pese a que esta caracterización parece hegemónica en los discursos docentes, emerge de forma incipiente un discurso subordinado que enuncia al vínculo como una relación un tanto más bidireccional. En este vínculo más bidireccional, ambos sujetos se transformarían recíprocamente y sería mediado por un tercero implícito o el Otro Histórico-Social (Pichón Rivière, 1985). Tal como indica Flores (2015), el Otro Histórico-Social está dado en el vínculo profesor-estudiante por la institución escolar, el sistema educativo o la sociedad en general. Sin embargo, de acuerdo con nuestros resultados, un nuevo aspecto que podría constituir el Otro Histórico es la movilización social por la educación que ha tenido a los estudiantes como protagonistas en los últimos años en Chile.

Es más, la movilización emerge como una figura importante en los discursos docentes y que tiende a invertir la relación profesor-estudiante, erigiendo al estudiante como sujeto que puede no solo aprender, sino también enseñar a sus maestros. Desde aquí se explica que, de forma incipiente, en los discursos se insinúe la posibilidad de una alianza entre profesor y estudiante. Dicha alianza se esboza pese a que en las movilizaciones estudiantiles de 2011 los discursos entre profesores y estudiantes dentro de la institución escolar han tendido a contraponerse, como señalan Cornejo e Insunza (2014).

Con las menciones a una eventual alianza entre ambos sujetos podríamos inferir cierta potencialidad en el vínculo en un sentido social e histórico, aunque sea una potencialidad muy embrionaria. Una potencialidad, no solo en el sentido político a partir de las movilizaciones, sino también una potencialidad en el mismo vínculo, en el proceso pedagógico que poco a poco comienza a cuestionarse el autoritarismo y la antidialogicidad propia de una relación sujeto-objeto de la educación bancaria (Freire, 1970). En ese sentido, profesor y estudiante aparecen en su dimensión transformadora, en una actitud dialogal de sujeto-sujeto (Freire, 1969), como en la pedagogía potencial (Quintar, 1998, 2009) en que el presente aparece como un futuro a construir (Zemelman, 2010).

En síntesis, los discursos sobre el vínculo entre profesor y estudiante constituyen un campo no exento de tensiones que da cuenta de posicionamientos de los docentes que transitan desde la unidireccionalidad hacia la bidireccionalidad de forma muy embrionaria. Estas tensiones podrían dar cuenta de un lugar paradójico del docente frente al encuentro 
con el sujeto estudiante, pero también de cambios históricos que se producen en el contexto educativo chileno en la última década.

\section{REFERENCIAS BIBLIOGRÁFICAS}

Albornoz, N., Silva, N., \& López, M. (2015). Escuchando a los niños: significados sobre aprendizaje y participación como ejes centrales de los procesos de inclusión educativa en un estudio en escuelas públicas en Chile. Estudios Pedagógicos, 41, Número especial, 81-96.

Assaél, J., Cornejo, R., Albornoz, N., Etcheberrigaray, G., Hidalgo F., Ligüeño, S., \& Palacios, D. (2015). La crisis del modelo educativo mercantil chileno: un complejo escenario. Currículo sem Fronteiras, 15(2), 334-335.

Assaél, J., Cornejo, R., González, J., Redondo, J., Sánchez, R., \& Sobarzo, M. (2011). La empresa educativa chilena. Educación y Sociedad, 32(115), 305-322.

Bruner, J. (2006). Realidad mental y mundos posibles. Barcelona: Gedisa.

Calsamiglia, H., \& Tusón, A. (1999). Las cosas del decir. Barcelona: Ariel S.A.

Canales, M. (2006). Metodologías de investigación social. Introducción a los oficios. Santiago: LOM.

Cornejo, R., \& Insunza, J. (2014). El sujeto docente ausente de las movilizaciones educativas. Algunas reflexiones para pensarlo a partir de un análisis del discurso docente. Psicoperspectivas, 12(2), 72-82.

Cornejo, R., Albornoz, N., Castañeda, L., Palacios, D., Etcheberrigaray, G., Fernández, R., Gómez, S., Hidalgo, F., \& Lagos, J. (2015). Las prescripciones del trabajo docente en el nuevo marco regulatorio de políticas educativas en Chile. Psicoperspectivas, 14(2), 72-83.

Donoso, S., Castro, M., \& Alarcón, J. (2015). Aspectos críticos en las propuestas sobre una nueva arquitectura de la educación pública chilena. Estudios Pedagógicos, 41(2), 305-324.

Fairclough, N. (1989). Languaje and power. Londres, Nueva York: Longman.

Fairclough, N. (2001). El análisis crítico del discurso como método para la investigación en ciencias sociales. En R. Wodak \& M. Meyer (Comps.), Métodos de análisis crítico del discurso (pp.179201). Barcelona: Gedisa.

Flick, U. (2004). Introducción a la Investigación Cualitativa. Madrid: Ediciones Morata.

Flores, A. (2015). Vínculo entre profesor y estudiantes en el marco del trabajo docente. Un análisis desde los discursos docentes pertenecientes a un liceo de la Región Metropolitana (Tesis para optar al grado de Magíster en Psicología Educacional). Universidad de Chile.

Freire, P. (1969). La educación como práctica de la libertad. Buenos Aires: Siglo XXI editores.

Freire, P. (1970). Pedagogía del Oprimido. Buenos Aires: Siglo XXI editores.

Freire, P. (1997). Pedagogía de la autonomía. Buenos Aires: Siglo XXI editores.

Martínez, D. (2007). Nuevas regulaciones, ¿nuevos sujetos? En M. Feldfeber \& D. Oliveira (Comps.), Políticas educativas y trabajo docente, nuevas regulaciones, ¿nuevos sujetos? (pp. 33-52). Buenos Aires: NOVEDUC.

Martínez, D., Collazo, M., \& Liss, M. (2009). Dimensiones del trabajo docente: Una propuesta de abordaje del malestar y el sufrimiento psíquico de los docentes en la Argentina. Educación y Sociedad, 30(107), 389-408.

Medel, E. (2003). Experiencias: Trabajo educativo con adolescentes. En H. Tizio (Ed.), Reinventar el vínculo educativo: aportaciones de la Pedagogía Social y del Psicoanálisis (pp. 73-83). Barcelona: Gedisa.

Murillo, F. J. (Ed.). (2003). La investigación sobre Eficacia Escolar en Iberoamérica. Revisión Internacional sobre el Estado del Arte. Bogotá: Convenio Andrés Bello.

Núñez, V. (2003). El vínculo educativo. En H. Tizio (Ed.), Reinventar el vínculo educativo: aportaciones de la Pedagogía Social y del Psicoanálisis (pp. 19-47). Barcelona: Gedisa.

Organización para la Cooperación y el Desarrollo Económicos [OCDE]. (2004). Revisión de Políticas 
Nacionales de Educación: Chile. Santiago: OCDE y Ministerio de Educación.

Pianta, R.C. (2001). STRSTM. Student-Teacher Relationships Scale. Florida: Psychological Assessment Resources.

Pichon-Rivière, E. (1985). Teoría del Vínculo. Buenos Aires: Ediciones Nueva Visión.

Quintar, E. (1998). La enseñanza como puente a la vida. Neuquén: Editorial Universidad de Comahue.

Quintar, E. (2009). Pedagogía de la Potencia y Didáctica no parametral [Entrevista realizada en mayo de 2009]. Recuperado desde http://www.ipecal.edu.mx/Biblioteca/Documentos/Documento2.pdf

Quintar, E., \& Zemelman, H. (2005). Pedagogía de la dignidad de estar siendo. [Entrevista realizada en marzo de 2005]. Recuperado desde http://tumbi.crefal.edu.mx/rieda/images/rieda-2005-1/ aula_magna.pdf

Quiroga, A. (2001) El universo compartido de Paulo Freire y Enrique Pichon-Rivière. Suplemento de 12, Universidad Popular Madres de Plaza de Mayo, julio 2001. Recuperado desde http://www. pagina12.com.ar/2001/suple/Madres/01-06/01-06-29/

Rosli, N., \& Carlino, P. (2015). Acciones institucionales y vinculares que favorecen la permanencia escolar de alumnos de sectores socioeconómicos desfavorecidos. Estudios Pedagógicos, 41(1), 257-274.

Valles, M. (1999). Técnicas cualitativas de investigación social. Reflexión metodológica y práctica profesional. Madrid: Editorial Síntesis.

Verger, A., Bonal, X., \& Zancajo, A. (2016). Recontextualización de políticas y (cuasi)mercados educativos. Un análisis de las dinámicas de demanda y oferta escolar en Chile. Archivos Analíticos de Políticas Educativas, 24(27), 1-27. doi:10.14507/epaa.24.2098

Vigotsky, L. (1978). El desarrollo de los procesos psicológicos superiores. Barcelona: Crítica.

Zemelman, H. (2010). Sujeto y Subjetividad: la problemática de las alternativas como construcción posible. Polis, 27, 1-11. doi:10.4000/polis.943 
